\title{
The modification of the muscle fatty acid profile by dietary supplementation with Aspergillus awamori in broiler chickens
}

\author{
Ahmed A. Saleh ${ }^{1,2}$, Yahya Z. Eid ${ }^{2}$, Tarek A. Ebeid ${ }^{2}$, Akira Ohtsuka ${ }^{1}$, Kumiko Hioki ${ }^{3}$, \\ Masahiro Yamamoto ${ }^{3}$ and Kunioki Hayashi ${ }^{1,3 *}$ \\ ${ }^{1}$ Department of Biochemical Science and Technology, Faculty of Agriculture, Kagoshima University, Kagoshima 890-0065, \\ Japan \\ ${ }^{2}$ Department of Poultry Production, Faculty of Agriculture, Kafrelsheikh University, 333516 Kafr El-Sheikh, Egypt \\ ${ }^{3}$ Biogenkoji Research Institute, Kirishima City, 876-15 Mizobe, Japan
}

(Submitted 1 September 2011 - Final revision received 23 November 2011 - Accepted 23 November 2011 - First published online 31 January 2012)

\begin{abstract}
The present study was conducted to show that dietary supplementation with a fungus, Aspergillus awamori, modifies muscle fatty acid profiles in broiler chickens. A total of thirty chicks, selected from a group of 100 chicks aged $15 \mathrm{~d}$, were divided into a control group and two treatment groups (ten birds per treatment). The control group was fed a basal diet, and the treatment groups were fed basal diets supplemented with A. awamori at levels of 0.05 and $0.2 \%$. From the start of the study at $15 \mathrm{~d}$, the birds were raised for an additional $12 \mathrm{~d}$, and growth and the muscle fatty acid profile were evaluated. Although feed intake was decreased by the fungus, body-weight gain and breast muscle weight were increased, and thus, feed efficiency was improved. Abdominal fat and plasma cholesterol and TAG were decreased, while plasma HDL-cholesterol and breast muscle fat content were increased. Interestingly, muscle $\alpha$-tocopherol content was increased and muscle thiobarbituric acid-reactive substances were decreased by $A$. awamori. Furthermore, there was an observed decrease in SFA and an increase in unsaturated fatty acids in the muscle fat due to the fungus feeding. The mRNA of fatty acid synthase, acetyl-CoA carboxylase and $\Delta-6$ desaturase in the muscle were all increased, while the mRNA of 3-hydroxyl-3-methylglutaryl-CoA reductase and carnitine palmitoyl transferase $1 \mathrm{~A}$ were decreased by the fungus. In conclusion, the present study clearly shows that the muscle lipid profile could be modified by the addition of $A$. awamori to the diet.
\end{abstract}

Key words: Aspergillus: Fatty acids: Broilers: Desaturase

PUFA play an important role in human nutrition because they help to reduce the incidence of lifestyle diseases, such as coronary artery disease, hypertension and diabetes, as well as certain inflammatory diseases, including arthritis and dermatitis $^{(1)}$. PUFA reduce the risk of CVD by controlling blood lipid levels and reducing platelet reactivity and aggregation ${ }^{(1)}$. There are various means of increasing intakes of PUFA, and one of these approaches is the enrichment or modification of staple foods. Global intakes of poultry meat are high, and poultry meat is amenable to the manipulation of its fatty acid composition.

Aspergillus awamori, a variant of Aspergillus niger, is one of the fungi called 'Koji' in Japan and has long been used for processing foods such as Shochu, a traditional Japanese liquor. The products containing $A$. niger are given GRAS (Generally Recognized As Safe) status from the Food and
Drug Administration ${ }^{(2)}$. Koji is known to produce enzymes such as amylase, protease, pectinase and lipase, and thus enhances the digestion of carbohydrates, proteins and lipids $^{(3)}$. In an earlier study ${ }^{(4)}$, feeding $A$. awamori increased digestibility and improved broiler performance. Koji also produces desaturase ${ }^{(5)}$ that is required for the synthesis of unsaturated fatty acids. Thus, it is expected that unsaturated fatty acids will increase and SFA will decrease in dietary fat by $A$. awamori feeding, which is due to its desaturase activity ${ }^{(6)}$. Based on the above expectation, we assumed that feeding the broilers with $A$. awamori might have the same effect of lipid modification in their muscles.

The present study was conducted to show whether the muscle fatty acid profile could be modified by feeding A. awamori in broiler chickens. This function of $A$. awamori may contribute to the production of healthier meat.

Abbreviations: ACC, acetyl-CoA carboxylase; CPT1A, carnitine palmitoyl transferase 1A; D6DES, $\Delta-6$ desaturase; FAS, fatty acid synthase; HMG-CoA, 3-hydroxyl-3-methylglutaryl-CoA; TBARS, thiobarbituric acid-reactive substances.

*Corresponding author: Dr K. Hayashi, fax +8199285 8652, email k4703774@kadai.jp 


\section{Materials and methods}

The animal experiment was conducted in accordance with the guidelines of Kagoshima University.

A total of 100, 1-d-old, male broiler chicks (Chunky strain) were supplied by a commercial hatchery (Kumiai Hina Center, Kagoshima, Japan). The chicks were housed in an electrically heated battery brooder and provided with water and a commercial starter diet $(23 \%$ crude protein and $12 \cdot 8 \mathrm{MJ} / \mathrm{kg}$; Nichiwa Sangyou Company) until $12 \mathrm{~d}$ of age. On day 12 , thirty birds with similar body weight were selected from a group of 100 birds and were housed individually in wire-bottomed aluminium cages $(49 \times 39 \times 59 \mathrm{~cm})$. The birds were preconditioned for $3 \mathrm{~d}$ before the treatment and fed on a basal diet. The experimental diets were formulated using mainly ground yellow maize and a soyabean meal, as shown in Table 1. The chicks were divided into three groups (ten in each group): a control group and A. awamori groups with two levels of koji $(0 \cdot 05$ and $0 \cdot 2 \%)$. The levels of A. awamori (0.01, 0.05 and $0 \cdot 10 \%)$ were previously examined and observed to have similar effects on broiler performance. Thus, in the present experiment, a higher level than that of the previous experiment $(0 \cdot 2 \%)$ was chosen. Koji was mixed into the basal diet. The number of $A$. awamori spores given was about $2.5 \times 10^{5}$ and $1 \times 10^{6} / \mathrm{g}$ feed for the diets of the 0.05 and $0.2 \%$ groups, respectively. The birds were given the experimental diets from 15 to $27 \mathrm{~d}$ of age. A. awamori was cultivated using steamed rice at the Biogenkoji Research Institute (Kirishima, Japan). The experiment was conducted in a temperature-controlled room with a $14 \mathrm{~h}$ light $-10 \mathrm{~h}$ dark cycle. Room temperature was kept at $25^{\circ} \mathrm{C}$ with a relative humidity from 50 to $70 \%$ throughout the experiment.

Table 1. Composition and nutrient analysis of the basal diet

\begin{tabular}{lr}
\hline Ingredients & \multicolumn{1}{c}{$\%$} \\
\hline Maize & $50 \cdot 19$ \\
Alfalfa meal & $2 \cdot 64$ \\
Soyabean meal & $39 \cdot 01$ \\
Maize oil & $4 \cdot 40$ \\
L-Lys HCl & $0 \cdot 01$ \\
DL-Met & $0 \cdot 18$ \\
Mineral mix & $3 \cdot 31$ \\
Vitamin mix† & $0 \cdot 26$ \\
Calculated analysis & \\
CP (\%) & $22 \cdot 60$ \\
ME (MJ/kg) & $12 \cdot 89$ \\
Ca (\%) & $1 \cdot 10$ \\
P (\%) & $0 \cdot 46$ \\
Na (\%) & $0 \cdot 26$ \\
Cl (\%) & $0 \cdot 25$ \\
\hline
\end{tabular}

$\mathrm{CP}$, crude protein; ME, metabolisable energy.

*The mineral premix supplied per kg feed: $154 \mathrm{mg} \mathrm{Mn}, 121 \mathrm{mg}$ $\mathrm{Zn}, 176 \mathrm{mg} \mathrm{Fe}, 33 \mathrm{mg} \mathrm{Cu}, 1.1 \mathrm{mg} \mathrm{I}, 0.7 \mathrm{mg} \mathrm{Se}$.

$\dagger$ The vitamin premix supplied per kg feed: $3784 \mu \mathrm{g}$ vitamin A, $0.066 \mu \mathrm{g}$ vitamin $\mathrm{D}, 110.11 \mu \mathrm{g}$ vitamin $\mathrm{E}, 12 \mathrm{mg}$ vitamin $B_{12}$, $1.37 \mathrm{mg}$ retinol, $0.13 \mathrm{mg}$ cholecalciferol, $6.50 \mathrm{mg}$ riboflavin, $2.60 \mathrm{mg}$ thiamin hydrochloride, $1.30 \mathrm{mg}$ pyridoxamine hydrochloride, $0.03 \mathrm{mg}$ cyanocobalamin, $10.40 \mathrm{mg}$ D-pantothenic acid, $26.00 \mathrm{mg}$ nicotinic acid, $1.05 \mathrm{mg}$ vitamin $\mathrm{K}_{3}, 0.52 \mathrm{mg}$ pteroylglutamic acid, $0.78 \mathrm{mg}$ choline chloride, $0.07 \mathrm{mg}$ biotin, $2.54 \mathrm{~g}$ sucrose.

\section{Sampling}

Body weight was recorded every $3 \mathrm{~d}$, and feed intake was recorded daily during the experimental period. At the end of the experimental period, the birds were slaughtered and then dissected to measure the weights of the breast muscle (pectoral superficial muscle) and abdominal fat. Blood samples were collected into heparinised test-tubes, quickly centrifuged at $5900 \mathrm{~g}$ for $10 \mathrm{~min}$ at $4^{\circ} \mathrm{C}$ to separate plasma, and stored at $-30^{\circ} \mathrm{C}$ until analysis.

\section{Biochemical analysis}

Blood and muscle. Total cholesterol levels, TAG, HDL- and LDL-cholesterol in plasma were measured by an automated Fuji DRY-CHEM 3500 (Fuji Medical Systems), according to the manufacturer's instructions. Concentration of muscle thiobarbituric acid-reactive substances (TBARS) was measured by the method of Ohkawa et al. ${ }^{(7)}$. The $\alpha$-tocopherol concentration of the muscle was determined by the Shimadzu HPLC model LC6A with a Shim-Pack CLC-ODS column $(6.0 \times 150 \mathrm{~mm})$ according to the method described by Faustman et al. ${ }^{(8)}$.

RNA extraction and real-time PCR. Total RNA was extracted from a piece of pectoral superficial muscle (about $100 \mathrm{mg}$ ) using an RNeasy ${ }^{\circledR}$ Fibrous Tissue Mini Kit (Qiagen), according to the manufacturer's protocol. RNA concentration and purity were determined spectrophotometrically using A260 and A280 values in a photometer (BioPhotometer; Eppendorf). The ratio of A260/A280 for all samples was between 1.8 and $2 \cdot 0$. Complementary DNA was synthesised at $800 \mathrm{ng} \mathrm{RNA} / 20 \mathrm{ml}$ of the reaction solution with the PrimeScript ${ }^{\circledR}$ RT Reagent Kit (Perfect Real Time; Takara) using the Program Temp Control System PC320 (Astec) with the following protocol: reverse transcription at $37^{\circ} \mathrm{C}$ for $15 \mathrm{~min}$; inactivation of RT at $85^{\circ} \mathrm{C}$ for $5 \mathrm{~s}$; refrigeration at $4^{\circ} \mathrm{C}$ for $5 \mathrm{~min}$. Real-time PCR primers were prepared as described by Nakashima et al. ${ }^{(9,10)}$. Gene expression was measured by real-time PCR using the 7300 Real Time PCR system (Applied Biosystems) with the SYBR ${ }^{\circledR}$ Premix Ex Taq ${ }^{\text {TM }}$ (Perfect Real Time; Takara). The thermal cycle was as follows: one cycle at $95^{\circ} \mathrm{C}$ for $10 \mathrm{~s}$ and sixty cycles at $95^{\circ} \mathrm{C}$ for $5 \mathrm{~s}$ and at $60^{\circ} \mathrm{C}$ for $31 \mathrm{~s}$. The expression of glyceraldehyde-3-phosphate dehydrogenase mRNA was used as an internal standard and was not significantly different between the two experimental groups. Results of gene expression are expressed as the percentage of the control value.

Fatty acid analysis. Lipids were extracted from the breast muscle $(20 \mathrm{~g})$ with a mixture of chloroform and methanol (2:1) in a separatory funnel. The funnel was shaken carefully for $15 \mathrm{~min}$ and left to stand for $4 \mathrm{~h}$ to separate the organic layer. The organic layer was collected, passed through a glass funnel containing anhydrous sodium sulphate and evaporated to near dryness using a vacuum evaporator ${ }^{(11)}$. Muscle total fat content was measured using the method described by Folch et al. ${ }^{(12)}$. The extracted fat $(100 \mathrm{mg})$ was put into a $10 \mathrm{ml}$ volumetric flask; $2.5 \mathrm{ml}$ of $0.5 \mathrm{~N}$ methanolic $\mathrm{NaOH}$ were added. The mixture was then heated on a steam bath until the fat globules entered the solution, or about $5 \mathrm{~min}$. Then, 
$4 \mathrm{ml} \mathrm{BF} / \mathrm{MeOH}$ were added to the flask and the mixture was boiled for $2 \mathrm{~min}$ in a water-bath. After cooling, a saturated $\mathrm{NaCl}$ solution was added to the mixture to reach a total volume of $8 \mathrm{ml}$. The mixture was then transferred to a separation funnel and extracted with $6 \mathrm{ml}$ petroleum diethyl ether. The diethyl ether phase was then evaporated on a waterbath at $60^{\circ} \mathrm{C}$. The obtained methyl ester of the fatty acid fraction was dissolved in $1 \mathrm{ml}$ hexane and used for fatty acid analysis. Fatty acids were separated by GC-MS (Thermo Fisher) on a capillary column $(30 \mathrm{~m} \times 0.25 \mathrm{~mm}$ in inner diameter) DB-1 coated with a $0 \cdot 25 \mu \mathrm{m}$ film of dimethyl polysiloxane ( $\&$ W Scientific) using $1 \mu \mathrm{l}$ of the sample. The temperature of the column was $150^{\circ} \mathrm{C}$ at the time of injection, then programmed at $5^{\circ} \mathrm{C} / \mathrm{min}$ to $250^{\circ} \mathrm{C}$ and maintained at that temperature for $5 \mathrm{~min}$. Injection was performed with a split ratio of 10:1. The flow rate was $1.0 \mathrm{ml} / \mathrm{min}$, He gas was used as a carrier and the injector temperature was $250^{\circ} \mathrm{C}$. The MS detection conditions were as follows: interface temperature, $230^{\circ} \mathrm{C}$; electron ionisation mode, $\mathrm{EI}+$; electron energy, $70 \mathrm{eV}$; full-scan acquisition mode; mass range, 33-450 a.m.u. Fatty acids were identified by using authentic standards and online NIST-library spectra.

\section{Statistical analysis}

The differences between the treatment groups and the control group were analysed with a general linear model using SPSS Statistics 17.0 (Statistical Packages for the Social Sciences, released 23 August 2008). Tukey's multiple comparison test was used to identify which treatment conditions were significantly different from each other at a significance level of $P<0.05$.

\section{Results}

The effects of $A$. awamori on body-weight gain, feed intake, feed conversion ratio and breast muscle weight are summarised in Table 2. A. awamori increased body-weight gain significantly $(P<0.05)$ in the $0.05 \%$ group, but not in the $0.2 \%$ group. Feed intake and the feed conversion ratio were significantly decreased $(P<0.01)$ in the $0.05 \% A$. awamori group, but not in the $0 \cdot 2 \%$ group. Breast muscle (pectoral superficial muscle) weight was significantly increased $(P<0.01)$ by the dietary supplementation of $A$. awamori despite the levels.

Plasma TAG, total cholesterol, HDL- and LDL-cholesterol concentrations are shown in Fig. 1(A)-(D), respectively. Plasma TAG, total cholesterol and LDL-cholesterol concentrations were significantly lower in the A. Awamori groups. On the other hand, plasma HDL-cholesterol concentration was increased by $A$. awamori.

The effects of A awamori on abdominal fat, breast muscle fat, $\alpha$-tocopherol and TBARS are shown in Table 3. Abdominal fat content was lower in both treatment groups. However, breast muscle fat content was increased in the treatment groups compared with the control group. Muscle $\alpha$-tocopherol content was higher and TBARS were lower in the treatment groups.

Fig. 2 shows the effect of $A$. awamori on the mRNA of fatty acid synthase (FAS; Fig. 2(A)), acetyl-CoA carboxylase (ACC; Fig. 2(B)), $\Delta$-6 desaturase (D6DES; Fig. 2(C)), carnitine palmitoyl transferase 1A (CPT1A; Fig. 2(D)) and 3-hydroxyl-3methylglutaryl-CoA (HMG-CoA) reductase (Fig. 2(E)) in the pectoral superficial muscle. The mRNA of FAS, ACC and D6DES were increased in the treatment groups but in the $0.2 \%$ group, the effects on ACC and D6DES were not statistically significant. On the other hand, mRNA of CPT1A and HMG-CoA reductase were decreased by the fungus but the effect on HMG-CoA reductase was not statistically significant when the level was $0 \cdot 2 \%$.

Fig. 3 shows how the fungus affected the major fatty acid profile of the skeletal muscle fat. Palmitic acid (Fig. 3(A)) was decreased in both $A$. awamori groups. Oleic acid (Fig. 3(B)) was $(P<0.05)$ significantly higher in the $0.2 \% A$. awamori group, but not in the $0.05 \%$ group. Linoleic acid (Fig. 3(C)) was significantly higher in both $A$. awamori groups. Linolenic acid (Fig. 3(D)) showed higher values in both $A$. awamori groups compared with the control group, and a significant increase was observed in the group treated with $0.05 \%$ A. awamori. Arachidonic acid (Fig. 3(E)) contents were significantly higher in the group treated with $0.2 \%$ A. awamori, but not in the $0.05 \%$ group.

Table 2. Effect of dietary supplementation of Aspergillus awamori on initial body weight (BW), body-weight gain (BWG), feed intake (FI), feed conversion ratio (FCR) and breast muscle weight (BMW)

(Mean values with their standard errors)

\begin{tabular}{|c|c|c|c|c|c|c|}
\hline & & & \multicolumn{4}{|c|}{ A. awamori } \\
\hline & \multicolumn{2}{|c|}{ Control } & \multicolumn{2}{|c|}{$0.05 \%$} & \multicolumn{2}{|c|}{$0.2 \%$} \\
\hline & Mean & SE & Mean & SE & Mean & SE \\
\hline Initial BW (g) & 399 & 9 & 399 & 9 & 399 & 9 \\
\hline BWG ( $g / 12 d)$ & $691^{\mathrm{b}}$ & 40 & $808^{a}$ & 15 & $704^{b}$ & 33 \\
\hline $\mathrm{FI}(\mathrm{g} / 12 \mathrm{~d})$ & $1197^{a}$ & 36 & $1057^{b}$ & 37 & $1098^{a, b}$ & 26 \\
\hline FCR & $1 \cdot 7^{\mathrm{a}}$ & 0.14 & $1 \cdot 3^{\mathrm{b}}$ & 0.04 & $1.5^{\mathrm{a}, \mathrm{b}}$ & 0.05 \\
\hline BMW (g/100 g BW) & $23 \cdot 9^{b}$ & $1 \cdot 1$ & $28 \cdot 8^{a}$ & 0.4 & $27 \cdot 3^{a}$ & 1 \\
\hline
\end{tabular}

${ }^{\mathrm{a}, \mathrm{b}}$ Mean values with unlike superscript letters were significantly different $(P<0.05)$. 

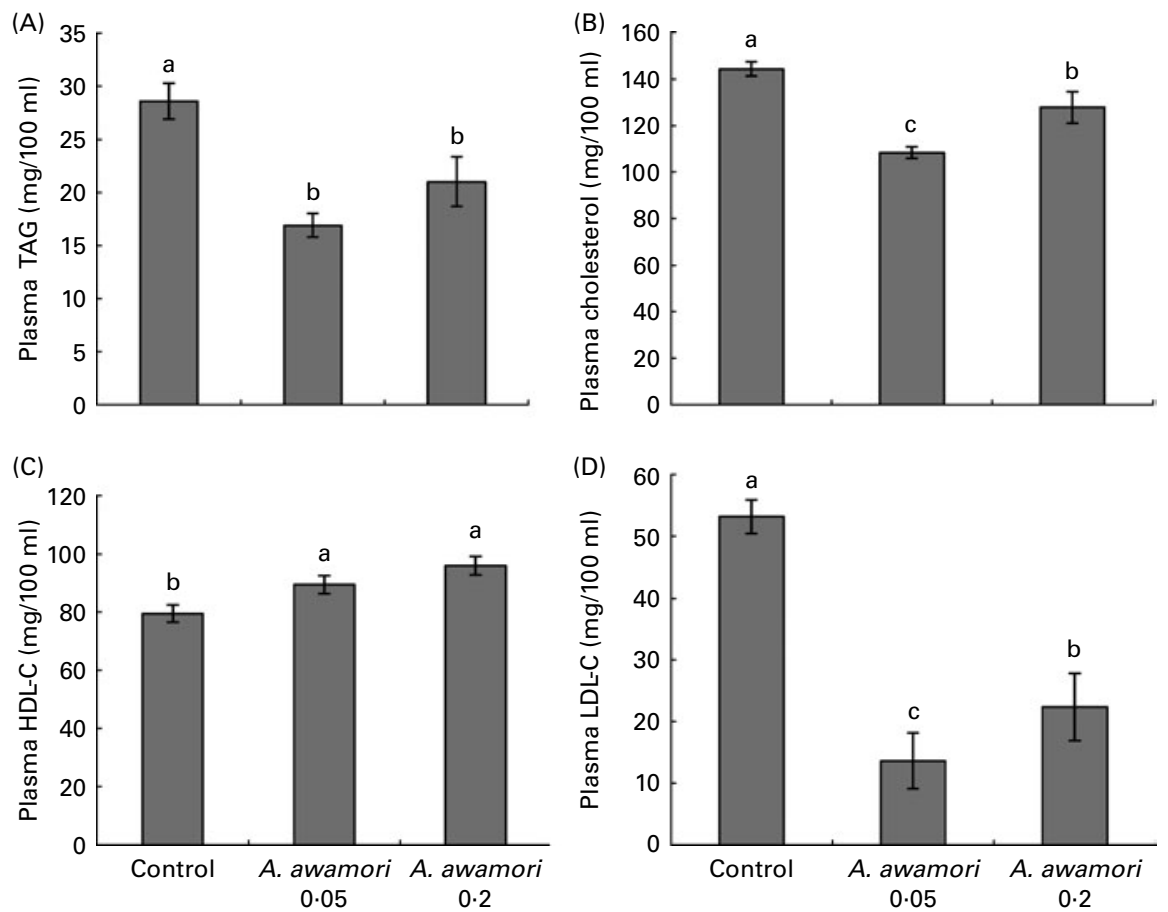

Fig. 1. Effect of dietary Aspergillus awamori on plasma (A) TAG, (B) cholesterol, (C) HDL-cholesterol (HDL-C) and (D) LDL-cholesterol (LDL-C). Values are means, with standard errors represented by vertical bars. ${ }^{a, b, c}$ Mean values with unlike letters were significantly different $(P<0.05)$.

\section{Discussion}

The aim of the present study was to show that the muscle fatty acid profile could be modified by $A$. awamori feeding. Broiler performance was improved by $A$. awamori feeding as reported previously ${ }^{(4)}$. Aspergillus could improve the nutritional value of the soyabean meal because the trypsin inhibitor contained in soyabean could be degraded by Aspergillus ${ }^{(13)}$. Birds do not produce enzymes such as cellulase and xylanase, which are required for the digestion of soluble NSP. Because Aspergillus produces these enzymes, it improves digestion, resulting in an increase in the metabolic energy of $\operatorname{diets}^{(14)}$. Indeed, we have reported that a mixture of cellulase, hemicellulase and pectinase improves digestion ${ }^{(15)}$. These may be the major reason for the more efficient feed utilisation in Aspergillus feeding. The decrease in feed intake and an improvement in feed conversion due to feeding Aspergillus were in agreement with the results of our previous studies ${ }^{(4)}$. Yamamoto et al. ${ }^{(16)}$ have noted that when broilers were fed on diets containing 0.05 and $1 \%$ Koji-feed, carcass weight was significantly increased, and breast muscle weight was increased while abdominal fat was decreased. The growth-promoting effect of Koji might be caused by a growth promoter produced by $A$. awamori, as reported by Kamizono et al. ${ }^{(17)}$. Breast muscle weight was also significantly increased by the fungus at the level of $0.05 \%$ $(P<0.05)$ but not at the level of $0.2 \%$, indicating that Koji also has a growth-inhibiting effect. The growth promoter may be active at the lower level than the growth inhibitor. The present results also indicate that the partition of nutrients is changed by Koji.

Table 3. Effect of dietary supplementation of Aspergillus awamori on abdominal fat and total fat, $\alpha$-tocopherol and thiobarbituric acid-reactive substances (TBARS) in pectoral superficial muscle (Mean values with their standard errors)

\begin{tabular}{|c|c|c|c|c|c|c|}
\hline & & & \multicolumn{4}{|c|}{ A. awamori } \\
\hline & \multicolumn{2}{|c|}{ Control } & \multicolumn{2}{|c|}{$0.05 \%$} & \multicolumn{2}{|c|}{$0.2 \%$} \\
\hline & Mean & SE & Mean & SE & Mean & SE \\
\hline Abdominal fat $(\mathrm{g} / 100 \mathrm{~g} \mathrm{BW})$ & $1.5^{\mathrm{a}}$ & 0.2 & $0.75^{\mathrm{b}}$ & 0.09 & $0.8^{b}$ & 0.08 \\
\hline Muscle total fat ( $\mathrm{g} / 100 \mathrm{~g}$ muscle) & $3.0^{\mathrm{b}}$ & $0 \cdot 2$ & $6 \cdot 0^{\mathrm{a}}$ & $1 \cdot 2$ & $7 \cdot 0^{\mathrm{a}}$ & $1 \cdot 0$ \\
\hline Muscle $\alpha$-tocopherol (mg/100 g muscle) & $0.13^{b}$ & 0.03 & $0.38^{\mathrm{a}}$ & 0.02 & $0.42^{\mathrm{a}}$ & 0.03 \\
\hline Muscle TBARS (nmol MDA/g muscle) & $27 \cdot 6^{\mathrm{a}}$ & 5 & $12^{\mathrm{b}}$ & 2 & $18 \cdot 4^{\mathrm{b}}$ & 2 \\
\hline
\end{tabular}

BW, body weight; MDA, malondialdehyde.

${ }^{a, b}$ Mean values with unlike superscript letters were significantly different $(P<0.05)$. 

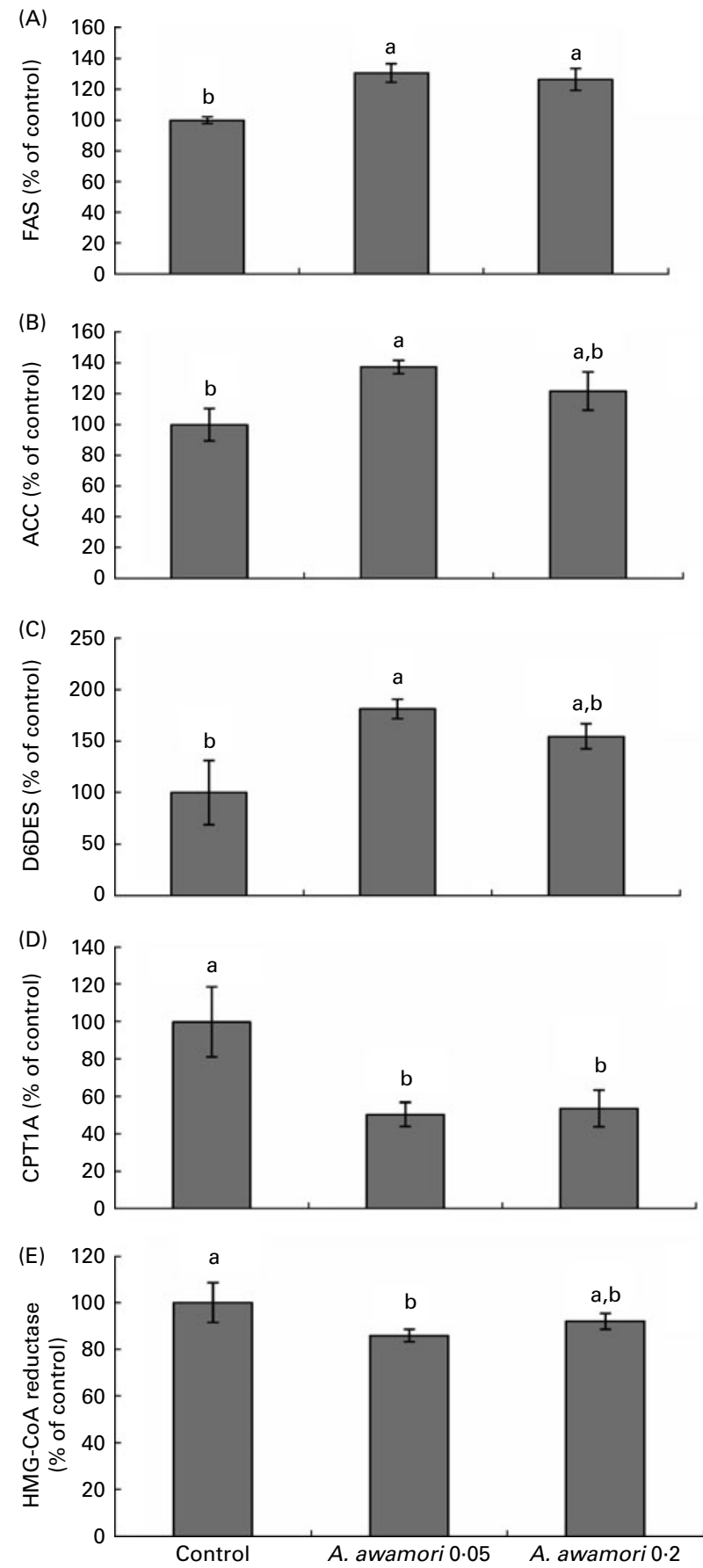

Fig. 2. Effect of dietary Aspergillus awamori on the mRNA of (A) fatty acid synthase (FAS), (B) acetyl-CoA carboxylase (ACC), (C) $\Delta-6$ desaturase (D6DES), (D) carnitine palmitoyl transferase 1A (CPT1A) and (E) 3-hydroxyl3-methylglutaryl-CoA (HMG-CoA) reductase contents in pectoral superficial muscle. Values are means, with standard errors represented by vertical bars. ${ }^{\mathrm{a}, \mathrm{b}}$ Mean values with unlike letters were significantly different $(P<0.05)$.

Dietary supplementation of $A$. awamori increased the mRNA contents of FAS, ACC and D6DES and decreased CPT1A, although higher dietary inclusion of $A$. awamori did not significantly influence the mRNA of ACC and D6DES. FAS, ACC and D6DES play important roles in the synthesis of PUFA ${ }^{(18)}$, and CPT1A is essential for fatty acid oxidation.
Aspergillus may also affect the activities of these enzymes in liver and adipose tissues and influence fat metabolism ${ }^{(19,20)}$. However, we have no data to support this assumption.

In the present experiment, abdominal fat and plasma cholesterol, TAG and LDL-cholesterol were decreased while
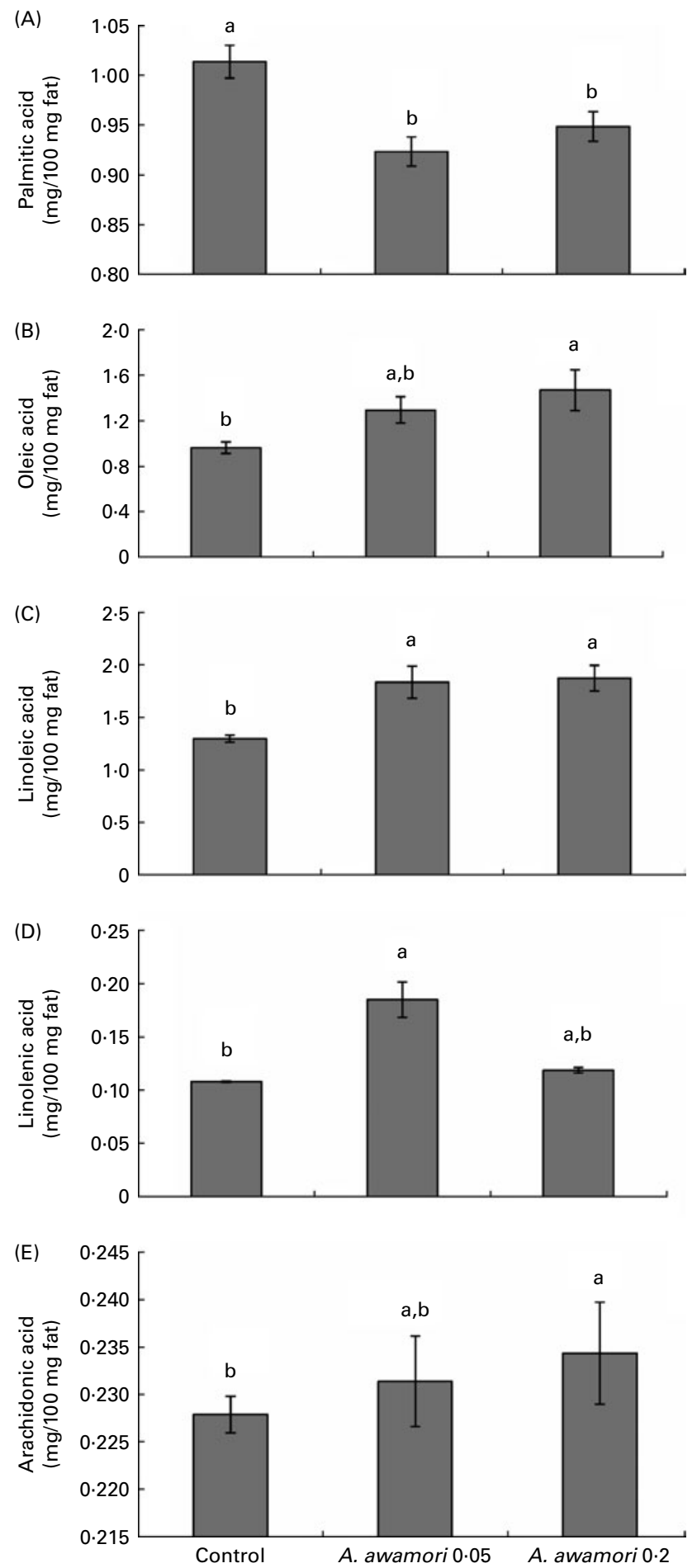

Fig. 3. Effect of dietary Aspergillus awamori on (A) palmitic acid, (B) oleic acid, (C) linoleic acid, (D) linolenic acid and (E) arachidonic acid contents in pectoral superficial muscle. Values are means, with standard errors represented by vertical bars. ${ }^{\mathrm{a}, \mathrm{b}}$ Mean values with unlike letters were significantly different $(P<0.05)$. 
plasma HDL-cholesterol was increased by the dietary supplementation of $A$. awamori. Kim et al. ${ }^{(21)}$ also found that $A$. oryzae at $0 \cdot 1 \%$ in the diet significantly lowered serum cholesterol and TAG in broiler chickens. The mechanism underlying the lowering effect of Aspergillus on plasma cholesterol and TAG could be related to an inhibitor of HMG-CoA reductase ${ }^{(22)}$. Indeed, mRNA of muscle HMG-CoA reductase was decreased by $A$. awamori feeding in the present experiment. It is well known that the HMG-CoA reductase inhibitor (Statin) was extracted from a fungus ${ }^{(23)}$ and Statin is widely used to decrease LDL-cholesterol and TAG and to increase HDL-cholesterol in the plasma. Muscle HMG-CoA reductase may also be responsible for the decrease in fat deposition.

Breast muscle TBARS were decreased, and muscle $\alpha$-tocopherol content was increased by $A$. awamori in the present experiment, indicating that the fungus has antioxidative properties. There was a negative correlation between muscle TBARS and $\alpha$-tocopherol content ${ }^{(24)}$. These results indicate that $A$. awamori produces antioxidative substances. In fact, Kaminishi et al. ${ }^{(25)}$ have found that several strains of Aspergillus produce antioxidative substances.

In the present study, PUFA concentrations in chicken muscle were increased by feeding $A$. awamori. On the other hand, palmitic acid, a SFA, was significantly decreased by $A$. awamori. This is important because PUFA play important roles in reducing the incidence of lifestyle diseases such as coronary artery diseases, hypertension and diabetes, as well as certain inflammatory diseases such as arthritis and dermatitis in humans ${ }^{(1)}$. Several studies have shown that oleic and linoleic acids are the most common unsaturated fatty acids produced by Aspergillus, and linoleic acid is a major constituent of fungal lipids ${ }^{(26-29)}$. Also, Aspergillus produces desaturase which converts SFA to unsaturated fatty acids ${ }^{(30)}$. Ignatius et $a l .{ }^{(31)}$ have reported that Aspergillus terreus produces linolenic acid, while the production of other PUFA has not been studied. It is probable that the increases in oleic, linoleic and linolenic acids in the muscle might have resulted from the intestinal activities of $A$. awamori. However, the higher level $(0.2 \%)$ of $A$. awamori did not change the linolenic acid content. As mentioned earlier, the higher level of $A$. awamori did not increase body-weight gain. The effect of $A$. awamori on linolenic acid metabolism may correlate with the growth-promoting action of $A$. awamori.

In conclusion, the present study clearly shows that the muscle lipid profile could be modified by the addition of $A$. awamori to the diet.

\section{Acknowledgements}

We are grateful to Kagoshima Chicken Foods Company, Limited (Kagoshima, Japan) for the supply of broiler chicks. This study received no specific grant from any funding agency in the public, commercial or not-for-profit sectors. All authors contributed equally to this work. A. A. S. conceived the research idea, conducted the animal experiment, chemical and biochemical analysis, and wrote and revised the manuscript. Y. Z. E. conceived the research idea and conducted the animal experiment. T. A. E. carried out the statistical analysis. A. O. conducted the chemical analysis. K. H. performed the biochemical analysis. M. Y. conceived the research idea and carried out the biochemical analysis. K. H. supervised the research and was responsible for the editing and revising of the manuscript. The authors declare that they have no conflicts of interest.

\section{References}

1. Simopoulos A (2000) Human requirement for $n$-3 polyunsaturated fatty acids. Symposium: role of poultry products in enriching the human diet with n-3 PUFA. Poult Sci 79, 961-970.

2. Bigelis R \& Lasure L (1987) Fungal enzymes and primary metabolites used in food processing. In Food and Beverage Mycology, 2nd ed., pp. 473-516 [LR Beuchat, editor]. Westport, CT: AVI.

3. Gracia M, Aranibar M, Lazaro R, et al. (2003) $\alpha$-Amylase supplementation of broiler diets based on corn. Poult Sci $\mathbf{8 2}$, 436-442.

4. Saleh AA, Eid Z \& Hayashi K (2011) Effects of feeding Aspergillus awamori and Aspergillus niger on growth performance and meat quality in broiler chickens. J Poult Sci 48, 201-206.

5. Mathivanan R, Selvaraj P, Nanjappan K, et al. (2006) Feeding of fermented soybean meal on broiler performance. In J Poult Sci 5, 868-872.

6. Richard A, Wilson AM, Calvo P, et al. (2004) Characterization of the Aspergillus parasiticus $\Delta^{12}$-desaturase gene: a role for lipid metabolism in the Aspergillus-seed interaction. Microbiology 150, 2881-2888.

7. Ohkawa H, Ohishi N \& Yagi K (1979) Assay for lipid peroxides in animal tissues by thiobarbituric acid reaction. Anal Biochem 95, 351-358.

8. Faustman C, Cassens R, Schaefer D, et al. (1989) Improvement of pigment and lipid stability in Holstein steer beef by dietary supplementation with vitamin E. J Food Sci $\mathbf{4 5}$, $858-862$.

9. Nakashima K, Yamazaki M \& Abe H (2005) Effects of serum deprivation on expression of proteolytic-related genes in chick myotube cultures. Biosci Biotechnol Biochem 69 , 623-627.

10. Nakashima K, Yakabe Y, Yamazaki M, et al. (2006) Effects of fasting and refeeding on expression of atrogin-1 and Akt/ FOXO signaling pathway in skeletal muscle of chicks. Biosci Biotechnol Biochem 70, 2775-2778.

11. Radwan SS (1978) Coupling of two dimensional thin layer chromatography with gas chromatography for the quantitative analysis of lipid classes and their constituent fatty acids. J Chromatogr Sci 16, 538-542.

12. Folch J, Lees M \& Sloane Stanley GH (1957) A simple method for the isolation and purification of total lipides from animal tissues. J Biol Chem 226, 497-509.

13. Hong K, Lee C \& Kim S (2004) Aspergillus oryzae GB-107 fermentation improves nutritional quality of food soybeans and feed soybean meals. J Med Food 7, 430-435.

14. Mohan B, Kadirvel R, Natarajan A, et al. (1996) Effect of probiotic supplementation on growth, nitrogen utilisation and serum cholesterol in broilers. Br Poult Sci 37, 395-401.

15. Tahir M, Saleh F \& Hayashi K (2006) Pectinase plays an important role in stimulating digestibility of a corn-soybean meal diet in broilers. J Poult Sci 43, 323-329.

16. Yamamoto M, Saleh F, Tahir M, et al. (2007) The effect of Koji-feed (fermented distillery by-product) on the growth 
performance and nutrient metabolizability in broiler. J Poult Sci 44, 291-296.

17. Kamizono T, Ohtsuka A \& Hayashi K (2010) Effects of feeding hexane-extracts of a shochu distillery by-product on skeletal muscle protein degradation in broiler chicken. Biosci Biotechnol Biochem 74, 92-95.

18. Serruys PW, Feyter PD \& Macaya C (2004) Fluvastatin for prevention of cardiac events following successful first percutaneous coronary intervention: a randomized controlled trial. J Am Med Assoc 287, 3215-3222.

19. Mersmann HJ (1998) Lipoprotein and hormone-sensitive lipases in porcine adipose tissue. J Anim Sci 76, 1396-1404.

20. Shen T, Wang JY, Zhao BD, et al. (1991) Biochemistry, pp. 151-167. Beijing: Higher Education Press.

21. Kim SH, Park SY, Yu DJ, et al. (2003) Effects of feeding Aspergillus oryzae ferments on performance, intestinal microflora, blood serum components and environmental factors in broiler. Kor J Poult Sci 30, 151-159.

22. Hajjaj H, Duboc P, Fay LB, et al. (2005) Aspergillus oryzae produces compounds inhibiting cholesterol biosynthesis downstream of dihydrolanosterol. FEMS Microbiol Lett $\mathbf{2 4 2}$, 155-159.

23. Endo A (1985) Compactin (ML-236B) and related compounds as potential cholesterol lowering agents that inhibit HMG-CoA reductase. J Med Chem 28, 401-405.
24. Maraschiello C, Sárraga C \& García Regueiro JA (1999) Glutathione peroxidase activity, TBARS, and $\alpha$-tocopherol in meat from chickens fed different diets. J Agric Food Chem 47, 867-872

25. Kaminishi Y, Egusa J \& Kunimoto M (1999) Antioxidant production from several xerophilous fungi used in "Katsuobushi" molding. J Natl Fish Univ 47, 113-120.

26. Kostner GM, Gavish D \& Leopold B (1989) HMG-CoA reductase inhibitors lower LDL cholesterol without reducing Lp(a). Circulation 80, 1313-1319.

27. Mazur P, Nakanishi K, El-Zayat AE, et al. (1991) Structure and synthesis of sporogenic psi factors from Aspergillus nidulans. J Chem Soc Chem Commun 20, 1486-1487.

28. Calvo AM, Gardner HW \& Keller NP (2001) Genetic connection between fatty acid metabolism and sporulation in Aspergillus nidulans. J Biol Chem 276, 25766-25774.

29. Tsitsigiannis DI, Zarnowski R \& Keller NP (2004) The lipid body protein, PpoA, coordinates sexual and asexual sporulation in Aspergillus nidulans. J Biol Chem 279, 11344-11353.

30. Garcia F, Garrido JA, Rodríguez RJ, et al. (2002) Cloning and molecular characterization of the delta6-desaturase from two echium plant species: production of GLA by heterologous expression in yeast and tobacco. Lipids 37, 417-426.

31. Ignatius S, Ira N \& Netty K (2010) Production of polyunsaturated fatty acids with Rhizomucor miehei by submerged fermentation. Asian J Food Agro-Ind 3, 293-300. 